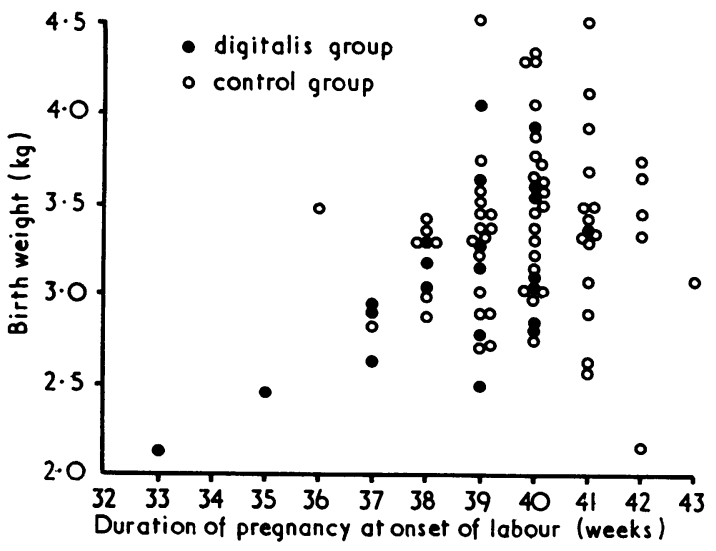

FIG. 2.-Birth weights of individual infants in both groups related to gestational age (completed weeks).

in the digitalis group was $300 \mathrm{~g}$ less than that of the infants in the control group ( $P<0.02$ using Student's $t$ test). The individual birth weights of infants in both groups were recalculated according to the criteria of Lubchenco et al. (1963), which takes into account differences in gestational age at birth and the sex of the infant, and also using the method recommended by Thomson et al. (1968), which includes, in addition to Lubchenco's criteria, correction factors for the differing maternal heights and weights. The percentile weights for gestational age of the infants were compared by means of $t$ tests and were similar in both groups of patients, suggesting that the difference in birth weight was purely reflective of the relative prematurity of the digitalis group and in no way indicated growth retardation. The total Apgar score at one minute was similar in both groups.

\section{Discussion}

Some similarity in response to cardiac glycosides of myocardium and myometrium was reported by Norris (1961), who showed increased tone and resistance to anoxia in digitalized myometrium in vitro. He was unable to show any effect on the time of onset of labour or duration of labour when digitalis in varying doses was given to primiparous patients for the last two weeks of pregnancy. He explained this observation by suggesting that digitalis decreases the efficiency of the normal heart and by analogy implied that digitalis could be expected only to increase the efficiency of a "failing" uterus. It has since been clearly shown, however, that digitalis increases the rate of intraventricular pressure development in patients without cardiac failure (Mason and Braunwald, 1963). We believe that the earlier onset and very much shorter labours in digitalized patients observed in this study might be consequent on the direct effect of digitalis on the myometrium exerted over a prolonged period.

We thank Professor A. C. Turnbull for his helpful advice and Dr. J. S. Crawford for posing the question.

\section{References}

Crawford, J. S. (1965). Principles and Practice of Obstetric Anaesthesia, p. 16. Oxford, Blackwell Scientific.

Lubchenco, L. O., Hansman, C., Dressler, M., and Boyd, E. (1963). Pediatrics, 32, 793.

McGarry, J., and Pearson, J. F. (1973). Lancet, 1, 483.

Mason, D. T., and Braunwald, E. (1963). Fournal of Clinical Investigation, 42, 1105 .

Norris, P. R. (1961). Fournal of Obstetrics and Gynaecology of the British Commonwealth, 68, 916 .

Robertson, J. D. (1972). In Integrated Obstetrics and Gynaecology for Postgraduates, ed. C. J. Dewhurst, p. 288. Oxford, Blackwell Scientific

Thomson, A. M., Billewicz, W. Z., and Hytten, F. E. (1968). Yournal of Obstetrics and Gynaecology of the British Commonwealth, 75, 903.

\title{
Serum Lipids in Cholelithiasis: Effect of Chenodeoxycholic Acid Therapy
}

\author{
G. D. BELL, B. LEWIS, A. PETRIE, R. HERMON DOWLING
}

British Medical fournal, 1973, 3, 520-522

\section{Summary}

Hypercholesterolaemia has been predicted as a possible complication of chenodeoxycholic acid treatment for gall stones. To exclude this, fasting serum lipids were measured in patients with stones before and at monthly intervals for six months after starting chenodeoxycholic acid. Before treatment half of a group of 36 patients with presumed cholesterol gall stones had serum cholesterol levels exceeding $260 \mathrm{mg} / 100 \mathrm{ml}$ or serum triglyceride values greater than $160 \mathrm{mg} / 100 \mathrm{ml}$ or both; these lipid levels were significantly greater than those in control subjects matched for age and sex. Treatment with chenodeoxycholic acid (0.5-1.5 g/day by mouth) did not change

Royal Postgraduate Medical School and Lipid Clinic, Hammersmith Hospital, London W12

G. D. BELL, M.SC., M.R.C.P., Research Fellow and Honorary Registrar B. LEWIS, M.D., M.R.C.PATH., Senior Lecturer in Chemical Pathology A. PETRIE, M.SC., Lecturer in Medical Statistics

R. HERMON DOWLING, M.D., M.R.C.P., Lecturer in Medicine and Consultant Physician serum cholesterol levels but did significantly reduce serum triglyceride concentrations from a pretreatment level of 118 ( \pm S.E. of mean 11.7) $\mathrm{mg} / 100 \mathrm{ml}$ to $95( \pm 7.2)$ $\mathrm{mg} / 100 \mathrm{ml}$ after six months of therapy. The mechanism of this triglyceride-lowering action of chenodeoxycholic acid is not known, but it may have therapeutic value in patients with hypertriglyceridaemia.

\section{Introduction}

Patients with cholesterol gall stones have a diminished bile acid pool (Vlahcevic et al., 1970) and a supersaturated bile in which there is insufficient bile acid and phospholipid to hold the cholesterol in solution (Admirand and Small, 1968). Treatment of such patients with the bile acid chenodeoxycholic acid repletes the bile acid pool (Danzinger, 1972), improves cholesterol solubility in bile (Thistle and Schoenfield, 1971), and promotes gall-stone dissolution (Bell et al., 1972; Danzinger et al., 1972). Against the benefits of gall-stone dissolution, however, must be set any complications of bile acid therapy, including the possible side effect of induced hypercholesterolaemia (Small, 1971). This was postulated because the major 
catabolic pathway for cholesterol is conversion to bile acids (Bloch et al., 1943). Exogenous bile acid feeding, therefore, could theoretically block endogenous bile acid synthesis from cholesterol. To exclude this we measured fasting serum cholesterol levels in a group of patients with presumed cholesterol gall stones before and at monthly intervals after starting chenodeoxycholic acid therapy. Fasting serum triglyceride levels were also measured and, where indicated, lipoprotein electrophoresis was carried out.

This paper reports our findings of a significantly higher incidence of both hypercholesterolaemia and hypertriglyceridaemia in untreated gall-stone patients when compared with matched controls. Treatment with chenodeoxycholic acid did not change the concentration of serum cholesterol but significantly reduced serum triglyceride levels.

\section{Subjects and Methods}

Untreated Gall-stone Patients. - Fasting serum cholesterol (Levin and Zak, 1964) and triglyceride (Cramp and Robertson, 1968) levels were measured in 36 untreated patients with radiologically proved gall stones. There were 28 women with a mean age of 49 years (range 24-75 years) and 8 men (mean age 52, range 37-65 years). Body weight was recorded in all patients. When increased levels of either serum cholesterol or serum triglycerides were noted semiquantitative lipoprotein electrophoresis (Chin and Blankenhorn, 1968) was carried out.

Matched Control Subjects. - The controls consisted of apparently healthy subjects working in a local light industry. They formed part of a large, randomly selected population previously studied by one of us (B.L.). None had symptoms suggesting cholelithiasis but gall stones were not excluded by cholecystography. Two controls matched for age and sex were selected for each gall-stone patient under the age of 65 (the retirement age in the control population). Thirty-one gall-stone patients and 60 control subjects were included in this part of the study.

The significance of observed differences was tested by a two-way analysis of variance with replication which led to an $F$ ratio. The results for men and women were then considered separately and the findings in the larger female group subdivided into those under and over the age of 45 .

Twenty-one of the patients with gall stones were treated with $0.5-1.5$ (usually $0 \cdot 75-1.0$ ) g chenodeoxycholic acid daily. Body weight and fasting serum lipids were measured before treatment and, when possible, at monthly intervals thereafter for six months. The baseline results were compared by the paired $t$ test with observations at one, three, and six months after therapy, when there were 19,18, and 15 patients respectively (patients entering the study over a one-year period).

\section{Results}

\section{FASTING SERUM LIPIDS IN UNTREATED PATIENTS}

Nine of the 36 gall-stone patients had serum cholesterol levels exceeding $260 \mathrm{mg} / 100 \mathrm{ml}$, 6 had serum triglyceride levels exceeding $160 \mathrm{mg} / 100 \mathrm{ml}$, while in 4 both serum lipids exceeded these values. Thus by these criteria 19 patients had hyperlipidaemia.

The overall results for the gall-stone patients (see table) showed that the mean serum cholesterol $(249 \pm$ S.E. of mean $10.8 \mathrm{mg} / 100 \mathrm{ml})$ and triglyceride $(135+13.4 \mathrm{mg} / 100 \mathrm{ml})$ levels were both significantly greater than the corresponding figures in the control subjects $(224+4.4 \mathrm{mg} / 100 \mathrm{ml} ; \mathrm{F}=14 \cdot 17$; $\mathrm{P}<0.01 ;$ and $103 \pm 5.4 \mathrm{mg} / 100 \mathrm{ml} ; \mathrm{F}=12.81 ; \mathrm{P}<0.01)$.

In men with gall stones the mean serum triglyceride level was considerably higher than in their age-matched controls. In women, whether grouped together or separated into two age groups, the trend to higher triglyceride levels was not statistically significant. Nevertheless, their mean serum cholesterol concentrations $(255 \pm 13.7 \mathrm{mg} / 100 \mathrm{ml})$ were significantly greater than those in the controls $(220 \pm 4.9 \mathrm{mg} / 100 \mathrm{ml} ; \mathrm{F}=24 \cdot 18$; $P<0.001)$. This difference was also present in the under-45 age group $(\mathrm{F}=8.15 ; \mathrm{P}<0.05)$ but was more evident in the older women $(F=17.92 ; P<0.01)$.

In general the results of lipoprotein electrophoresis showed that patients with hypercholesterolaemia had an increased beta band while patients with hypertriglyceridaemia had an increased pre-beta band.

\section{BODY WEIGHT IN UNTREATED PATIENTS}

When men and women were considered together the gall-stone patients (mean body weight $70.8 \pm 2.3 \mathrm{~kg}$ ) were not significantly heavier than the matched control subjects $(66.0 \pm 1.4 \mathrm{~kg})$. However, body weight was significantly greater in men $\mathbf{7 8 . 4} \pm$ $4.0 \mathrm{~kg} ; \mathrm{F}=11.9 ; \mathrm{P}<0.01)$ and in younger women $(68.7 \pm 4.3$ $4.3 \mathrm{~kg} ; \mathrm{F}=7 \cdot 12 ; \mathrm{P}<0.05)$ with gall-stones than in the corresponding control subjects, who weighed $70.6 \pm 1 \cdot 2 \mathrm{~kg}$ and $61.3 \pm 1.9 \mathrm{~kg}$ respectively. There was no significant difference between female patients aged 45-65 years (body weight $67 \cdot 6 \pm$ $3 \cdot 2 \mathrm{~kg})$ and their controls $(67 \cdot 8 \pm 3 \cdot 1 \mathrm{~kg})$.

\section{EFFECTS OF TREATMENT ON FASTING SERUM LIPIDS}

The fasting serum lipids before and after chenodeoxycholic acid (0.5-1.5 g/day) are shown in the chart. There was no change in mean serum cholesterol levels before treatment and at monthly intervals after therapy. The pretreatment serum triglyceride levels, however, fell from $118( \pm 11 \cdot 7) \mathrm{mg} / 100 \mathrm{ml}$ before treatment to $102( \pm 10 \cdot 2), 97( \pm 6 \cdot 6)$, and $95( \pm 7 \cdot 2) \mathrm{mg} / 100 \mathrm{ml}$ after one, three, and six months respectively of bile acid feeding. The statistical significance of the difference between the results before and after treatment became greater with each successive month $(t=2.77, \mathrm{P}<0.05$ at three months; and $t=3.76$, $\mathbf{P}<0.005$ after six months of therapy). There was no significant change in body weight during treatment $(65.0 \pm 4.2 \mathrm{~kg}$ before and $67.6 \pm 2.9 \mathrm{~kg}$ after treatment).

\section{Discussion}

These results show that before treatment half of a group of 36 patients with gall stones (presumed to consist predominantly

Fasting Serum Cholesterol and Triglyceride Levels (Means \pm S.E. of Means in mg/100 ml) in Patients with Cholesterol Gall stones and in Control Subjects matched for Age and Sex. Numbers of Subjects studied are given in Parentheses

\begin{tabular}{|c|c|c|c|c|c|c|}
\hline & & \multirow{2}{*}{ Men and Women } & \multirow{2}{*}{ Men } & \multicolumn{3}{|c|}{ Women } \\
\hline & & & & All & Age $<45$ yr & Age 45-65 yr \\
\hline $\begin{array}{l}\text { Serum cholesterol }(\mathrm{mg} / 100 \mathrm{ml}) \\
\text { Serum triglyceride }(\mathrm{mg} / 100 \mathrm{ml})\end{array}$ & $\begin{array}{l}\text { Patients } \\
\text { Controls } \\
\text { Significance } \\
\text { Patients } \\
\text { Controls } \\
\text { Significance }\end{array}$ & $\begin{array}{c}249 \pm 10 \cdot 8(31) \\
224 \pm 4 \cdot 4(60) \\
F=14 \cdot 17 ; \mathrm{P}<0 \cdot 01 \\
135 \pm 13 \cdot 4(31) \\
103 \pm 5 \cdot 4(60) \\
\mathrm{F}=12 \cdot 81 ; \mathrm{P}<0.01\end{array}$ & $\begin{array}{c}233 \pm 13.8(8) \\
237 \pm 8.9(16) \\
N . S .9(8) \\
155 \pm 37.9(8) \\
112 \pm 8.9(16) \\
\mathrm{F}=6.69 ; \mathrm{P}<0.05\end{array}$ & $\begin{array}{c}255 \pm 13 \cdot 7(23) \\
220 \pm 4 \cdot 9(44) \\
\text { F }=24 \cdot 18 ; \mathrm{P}<0 \cdot 001 \\
128 \pm 12 \cdot 8(23) \\
99 \pm 6 \cdot 2(44) \\
\text { N.S. }\end{array}$ & $\begin{array}{c}240 \pm 16 \cdot 5(12) \\
211 \pm 6 \cdot 8(24) \\
F=8 \cdot 15 ; P<0.05 \\
117 \pm 12 \cdot 9(12) \\
94 \pm 7.4(24) \\
\text { N.S. }\end{array}$ & $\begin{array}{c}271 \pm 21.9(11) \\
230 \pm 6.5(20) \\
F=17.92 ; P<0.01 \\
139 \pm 22.9(11) \\
106 \pm 10.4(20) \\
\text { N.S. }\end{array}$ \\
\hline
\end{tabular}



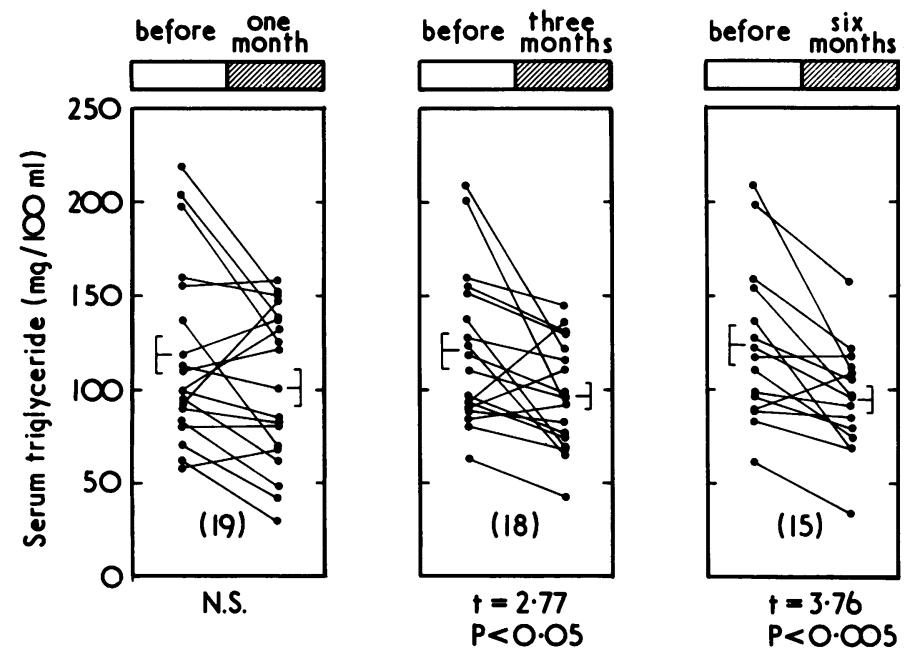

Fasting serum triglyceride levels in patients with gall stones before and after one, three, and six months of treatment with chenodeoxycholic acid. Mean values $t$ S.E. of means are shown by "E"-shaped symbols; numbers of patients are given in parentheses.

of cholesterol) had either serum cholesterol levels exceeding $260 \mathrm{mg} / 100 \mathrm{ml}$ or serum triglyceride levels exceeding $160 \mathrm{mg} /$ $100 \mathrm{ml}$ or both. Treatment of these patients with oral chenodeoxycholic acid not only improved cholesterol solubility in bile and promoted gall-stone dissolution (Bell et al., 1972) but also significantly lowered fasting serum trigylceride levels. However, the postulated development of hypercholesterolaemia due to bile acid feeding (Small, 1971) did not occur. There was no change in the mean fasting serum cholesterol levels measured at monthly intervals during a six-month period of treatment.

The mechanism for hypercholesterolaemia in untreated gall-stone patients is unknown. Most previous investigators have shown no relation between serum cholesterol levels and susceptibility to cholesterol gall-stones (Gardner and Gainsborough, 1930; Piper and Orrid, 1956; Friedman et al, 1966; Comess et al., 1967). Two studies have failed to show a relation between serum and biliary cholesterol concentrations (van der Linden and Norman, 1967; Thorbjarnson, 1969). In our series of gall-stone patients higher serum cholesterol levels were found mainly in older women, while male patients tended to show hypertriglyceridaemia, as has been suggested by Scherstén et al. (1972). The men were more often obese, this being a common feature of patients with primary hypertriglyceridaemia. Previous epidemiological studies have shown that the risk of gall stones is about twice as great in those who are $20 \%$ above median weight for their sex-height group (Friedman et al., 1966) as in those who are $10 \%$ below this weight; careful dietary studies (Sarles et al., 1957; Sarles et al., 1969) have shown that gall-stone patients have a significantly higher calorie intake than control subjects. Obesity, however, is by no means always present in patients with gall stones (Comess et al., 1967; Sarles et al., 1969; Wheeler et al., 1970). Other factors associated with hypertriglyceridaemia were not conspicuous in the present group of patients. Only one patient admitted to moderately heavy alcohol intake and one had diabetes mellitus which was controlled with diet and oral hypoglycaemic agents.

It was speculated that bile acid administration might cause hypercholesterolaemia both by enhancing intestinal absorption of cholesterol and by inhibiting hepatic conversion of cholesterol to bile acids (Small, 1971). Opposing these possible mechanisms is the depression of small-intestinal cholesterol synthesis (a major source of exchangeable cholesterol) by bile acids (Dietschy, 1968) and the fact that hepatic cholesterol accumulation would inhibit its own synthesis from acetate (Wilson, 1972). Individual bile acids may differ in their effect on cholesterol metabolism. In rats taurocholate suppressed cholesterol 7-alphahydroxylase activity (the rate-limiting enzyme in the conversion of cholesterol to bile acids) but taurochenodeoxycholate did not
(Mosbach, 1972). We have found no change in serum cholesterol in patients given chenodeoxycholic acid, but effects on extravascular pools remain possible.

Chenodeoxycholic acid had a small but significant effect in reducing serum triglyceride concentrations. In most patients this occurred within the normal range, but it was also evident in three patients with hypertriglyceridaemia. This was not associated with change in body weight and the mechanism whereby chenodeoxycholic acid lowered serum triglyceride levels is unknown. Several lines of evidence suggest that there may be a reciprocal relation between bile acid pool size and plasma triglyceride concentrations. Before treatment patients with cholesterol gall stones have a diminished bile acid pool (Vlahcevic et al., 1970), and in our patients the pretreatment serum triglyceride levels were high. Conversely, after bile acid feeding the serum triglyceride levels fell. There is other indirect evidence that bile acids may influence triglyceride metabolism. For example, treatment with the anion-binding resin cholestyramine depletes bile acid stores and after cholestyramine therapy there is a temporary rise in serum triglyceride levels (Jones and Dobrilovic, 1969). Similarly, ileal resection depletes the bile acid pool (Abaurre et al., 1969; Dowling et al., 1970), and patients with ileectomy may occasionally have hypertriglyceridaemia (Press et al., 1972).

The effect of chenodeoxycholic acid on serum triglyceride levels could be due to either depressed synthesis or more rapid clearance. Clearance has not been studied but several investigations suggest that bile acids may affect triglyceride synthesis. Bile acids may inhibit the re-esterification of monoglycerides and fatty acids to triglycerides in rat small bowel (Dietschy, 1968; Senior, 1969) but whether they affect de novo intestinal triglyceride synthesis has yet to be established. It has also been shown that cholic acid depresses fatty acid synthesis in pigeon liver (Seitz and Brand, 1961), but again hepatic triglyceride synthesis has not been studied.

A third possibility concerns hepatic phospholipid synthesis. Triglycerides and phospholipids share a common precursor, the diglycerides, and since bile acids increase hepatic phospholipid synthesis (Nilsson and Schersten, 1970) the diversion of diglyceride to this pathway could reduce the throughput to triglyceride.

Whatever the mechanism for the triglyceride-lowering effect of chenodeoxycholic acid, treatment with this bile acid not only promotes gall-stone dissolution but may also be useful as a treatment for hypertriglyceridaemia.

We thank the patients for their co-operation and Mrs. Hazel Creed for secretarial help. We thank Weddel Pharmaceuticals for supplies of chenodeoxycholic acid and for financial support (G.D.B.). This study was also supported by the Medical Research Council through the Intestinal Malabsorption Group (R.H.D.).

Requests for reprints should be addressed to R.H.D.

\section{References}

Abaurre, R., Gordon, S. G., Mann, J. G., and Kern, F., jun. (1969). Gastroenterology, 57, 679 .

Admirand, W. H., and Small, D. M. (1968). Fournal of Clinical Investigation, 47, 1043.

Bell, G. D., Whitney, B., and Dowling, R. H. (1972). Lancet, 2, 1213. Bloch, K., Berg, B. N., and Rittenberg, D. (1943). Fournal of Biological

Chin, H. P., and Blankenhorn, D. H. (1968). Clinica Chimica Acta, 20, 305. Comess, L. J., Bennett, P. H., and Burch, T. A. (1967). New England fournal of Medicine, $277,894$.

Cramp, D. C., and Robertson, C. (1968). Analytical Biochemistry, 25, 246. Danzinger, R. G. (1972). In Bile Acids in Human Diseases, ed. P. Back and W. Gerok, p. 167. Stuttgart, Schattauer.

Danzinger, R. G., Hofmann, A. F., Schoenfield, L. J., and Thistle, J. L. (1972). New England Fournal of Medicine, 286, 1 .

Dietschy, J. M. (1968), Fournal of Clinical Investigation, 47, 286. ling, R. H., Mack, E.,

Friedman, G. D., Kannel, W. B., and Dawber, T. R. (1966). Fournal of Chronic Diseases, 19, 273.

Gardner, J. A., and Gainsborough, H. (1930). Quarterly fournal of Medicine,

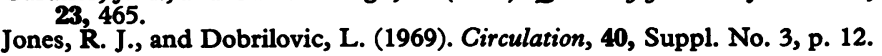


Levin, J., and Zak, B. (1964). Clinica Chimica Acta, 10, 381.

Mosbach, E. H. (1972). In Bile Acids in Human Diseases, ed. P. Back and W. Gerok, p. 89. Stuttgart, Schattauer.

Nilsson, S., and Schersten, T. (1970). European fournal of Clinical Investigation, 1, 109.

Piper, J., and Orrid, L. (1956). American fournal of Medicine, 21, 34.

Press M., Miller, P., Shimoyama, T., Kikuchi, H., and Thompson, G. R. (1972). European fournal of Clinical Investigation, 2, 301

Sarles, H., Chalvet, M., Ambrosi, D., and D'Ortoli, G. (1957). Semaine des Hôpitaux de Paris, 33, 3424.

Sarles, H., et al. (1969). American fournal of Digestive Diseases, 14, 531 Scherstén, T., Alling, C., Cahlin, E., Jonssen, J., and Nilsson, S. (1972) Abstract of 9th International Congress on Gastroenterology.
Seitz, W., and Brand, V. (1961). Klinische Wochenschrift, 39, 891.

Senior, J. R. (1969). In Bile Salt Metabolism, ed. E. Schiff, J. B. Carey, jun., and J. M. Dietschy, p. 56. Springfield, Illinois, Thomas.

Small D. M. Dint

Thistle, J. L., and Schoenfield, L. J. (1971) New England fournal of Medicine, 284, 177 .

Thorbjarnson, B. (1969). Archives of Surgery, 98, 372.

van der Linden, W., and Norman, A. (1967). Acta Chirurgica Scandinavica, $133,307$.

Vlahcevic, Z. R., Bell, C. C., jun., Buhac, I., Farrar, J. T., and Swell, L. (1970). Gastroenterology, 59, 165.

Wheeler, M., Hill, S. L. L., and Laby, B. (1970). Gut, 11, 430.

Wilson, J. D. (1972). Archives of Internal Medicine, 130, 493.

\section{PRELIMINARY COMMUNICATIONS}

\section{Some Actions of Growth Hormone Release Inhibiting Factor}

\section{Aa. PRANGE HANSEN, H. ØRSKOV, K. SEYER-HANSEN K. LUNDBEK,}

British Medical fournal, 1973, 3, 523-524

\section{Summary}

Preliminary studies indicate that somatostatin (SRIF, somatropin release inhibiting factor) can suppress exercise-induced plasma growth hormone rise in normal subjects as well as in diabetics.

\section{Introduction}

Three years ago we proposed the hypathesis that growth hormone overproduction is a casual factor in the development of diabetic angiopathy. It is a working hypothesis based on the facts that the plasma growth hormone level is very high and fluctuates throughout life in diabetic patients and that surgical removal of the source of growth hormone production inhibits the funther development of vascular changes in severe long-term diabetic angiopathy (Lundbæk et al., 1970; Hansen, 1972)

The practical conclusion of this working hypothesis is that attempts at growth hormone suppression by pharmacological means in diabetic patients should be pursued, particularly since hypophysectomy is not an ideal procedure for many reasons. The exercise test developed in our laboratory (Hansen, 1972) has been used in this search. Exercise is a normally occurring stimulus to growth hormone secretion in daily life. In a study with a practical therapeutic aim this test is to be preferred to artificial stimuli such as insulin-induced hypoglycaemia or the administration of arginine, levodopa, or other compounds.

Using the exercise test we have assessed many commercially available drugs acting in the hypothalamic area, especially various psychotropic drugs, on the assumption that one or more of these compounds might influence the assumed

\footnotetext{
Second University Clinic of Internal Medicine, Kommunehospitalet, Aarhus, Denmark

Aa. PRANGE HANSEN, M.D., Senior Registrar in Medicine

H. ФRSKOV, M.D., Director, Laboratory of Experimental Medicine

K. SEYER-HANSEN, M.D., Reader in Medicine

K. LUNDBEK, M.D., Professor of Medicine
}

growth hormone releasing facor in the hypothalamus. Only amitriptyline seems to have any effect, but it is much too slight. Alpha-adrenergic blocking agents suppress gnowth hormone during exercise in diabetic patients (Hansen, 1971) but only when given intravenously.

Recently a naturally occurring hypothalamic growth hormone release inhibiting factor-somatostatin or SRIF (somatotnopin release inhibiting factor)-has been found and isolated as a tetradecapeptide by Guillemin and his co-workers (Brazeau et al., 1973). Preliminary results obtained with this compound in seven normal subjects and in nine diabetics are presented here. The non-diabetics were all doctors from the department. The diabetics and the controls were all normal weight, men, age range 25-39 years. As little is known about possible effects of somatostatin the drug was tested on several of the controls before it was given to the diabetic patients. The only side effects observed were a slight feeling of oppression in the chest of some normal and diabetic subjects immediately after the injection of somatostatin and in all cases a rise in blood pressure of 10-15 mm Hg accompanied by a fall in pulse rate of 10-20 beats/min lasting for less than five minutes. All the subjects were fully informed of the experimental nature of the investigation and of the possible side effects. Only patients who had had diabetes for less than five years and had normal blood pressure were investigated.

\section{Methods and Results}

The exencise test consisted in a control period, an exercise period of $450 \mathrm{~kg} / \mathrm{min}$ for 40 minutes on a bicycle ergometer, and a post-exencise period. It was done once with somatostatin and one without.

In most experiments somatostatin was given as a rapid intravenous injection (two minutes) of $250 \mu \mathrm{g} 10$ minutes before beginning exercise, followed by a continuous infusion of 250 $\mu \mathrm{g}$ for the next 60 minutes. In four experiments-all on nondiabetics-somatostatin was given in six short injections every 10 minutes from 10 minutes before to $\mathbf{4 0}$ minutes after starting exercise. The results were not appreciably different in these two experiments.

Plasma growth hormone was determined with a single antibody radioimmunoassay employing wick-chromatography (Ørskov et al., 1968). A Wilhelmi preparation (HS 1216 C) was used for growth hormone standards.

The average curve for the seven non-diabetics is shown in fig. 1. The average rise was lower when somatostatin was given. The suppression is statistically significant when using the paired $t$ test at the beginning of the work period; after 20,30, and 40 minutes of work; and 10,50, and 60 minutes after cessation of work $(2 \mathrm{P}<0.05)$ 